\title{
Supramolecular poly(L-lactide)s containing terpyridine metal complexes
}

\author{
Marcel Heller ${ }^{1,2}$, Ulrich S. Schubert ${ }^{2,3 *}$ \\ ${ }^{1}$ Lehrstuhl für Makromolekulare Stoffe, TU München, Lichtenbergstr. 4, \\ 85747 Garching, Germany \\ ${ }^{2}$ Center for NanoScience, LMU München, Amalienstr. 54, 80799 München, Germany \\ ${ }^{3}$ Laboratory of Macromolecular and Organic Chemistry, Dutch Polymer Institute \\ (DPI), Eindhoven University of Technology, P.O. Box 513, 5600 MB Eindhoven, \\ The Netherlands; Fax +31 (0) 402474186; u.s.schubert@tue.nl
}

(Received: April 17, 2001; published: June 4, 2002)

\begin{abstract}
Chiral poly(L-lactide)s end-capped with a novel terpyridine ligand are synthesized by a controlled coordinative polymerization procedure. The resulting well-characterized macroligands can be complexed under phase-transfer conditions with iron(II) ions to form well-defined supramolecular poly(L-lactide) complexes. The outstanding stability of such coordinative polymers enables the full characterization by gel permeation chromatography (GPC) and MALDI-TOF mass spectrometry. In addition, in-line diode array UV-Vis spectroscopy coupled to GPC was carried out to verify the formation of the poly(ester) complexes.
\end{abstract}

\section{Introduction}

Due to the sensitivity of metal complexes towards physical, electrochemical and optical influences, the integration of coordinative ligands into macromolecules has become an important approach for the preparation of novel functional polymers. Therefore, chelating compounds such as 2,2'-bipyridines or 2,2':6',2"-terpyridines are being utilized as suitable ligands [1]. They enable the formation of rigid coordination polymers. In order to obtain well-defined supramolecular polymer structures, living and controlled polymerization methods may be performed, using functionalized biand terpyridines as initiating units [2]. This concept is already well established for the preparation of poly(oxazoline)s and was transferred to atom transfer radical polymerization (ATRP) of styrene as well as to the controlled polymerization of lactides and caprolactones [3-7]. In this context 2,2':6',2"-terpyridine-containing poly(oxazoline)s and poly(lactide)s resulted in stable iron(II)-coordinated structures [8,9].

Poly(lactide)s are biodegradable polyesters, which are prepared from 3,6-dimethyl1,4-dioxan-2,5-dione by ring-opening polymerization techniques, and found promising applications in medicine and tissue engineering $[10,11]$. We already reported on a 'convergent' approach towards chiral terpyridine-containing poly $(L-$ lactide) complexes, by initiation of lactide polymerization with hydroxy-functionalized terpyridine and the following polymer analogous complexation with metal ions [9]. In this work we describe the synthesis of a novel hydroxymethyl-functionalized 
terpyridine ligand (with an additional phenyl moiety between the terpyridine unit and the hydroxymethyl functionality), which is then used for the preparation of welldefined poly(L-lactide)s and the corresponding supramolecular iron(II) complexes. In order to verify the incorporation of the ligand function into the resulting polymer and to proof the successful formation of the metal-containing dimers, various characterization methods were applied.

\section{Results and discussion}

The synthesis of the novel ligand 4'-(4-hydroxymethylphenyl)-2,2':6',2"-terpyridine, 3, starts from the well-known 4'-(4-bromomethylphenyl)-2,2':6',2"-terpyridine, 1 . Thereby it turned out that the direct conversion with alkali (e.g., $\mathrm{NaOH}, \mathrm{K}_{2} \mathrm{CO}_{3}, \mathrm{AgNO}_{3} / \mathrm{H}_{2} \mathrm{O}$ ) did not or not likely succeed. Hydrolysis of benzyl halogenides follows a $S_{N} 1$ mechanism. Therefore, successful conversion beneath its concentration depends on the reactivity of compound 1 , which seems to be rather low because of the electronwithdrawing $p$-terpyridine substituent. Finally, the indirect path via acetylation of 1 and the following saponification of the acetate 2 turned out to be most suitable, and the 4'-(4-hydroxymethylphenyl)-2,2':6',2"-terpyridine, 3, was obtained in $56 \%$ overall yield (Fig. 1).

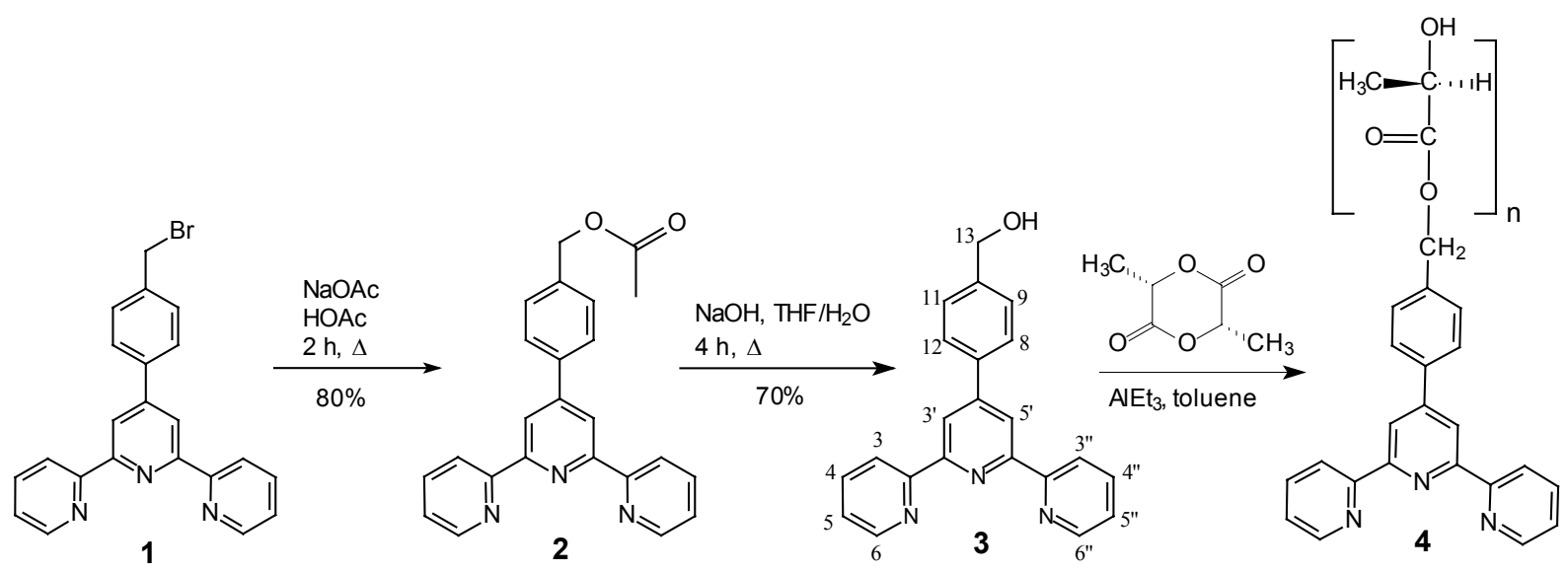

Fig. 1. Synthesis of 4'-(4-hydroxymethylphenyl)-2,2':6',2"-terpyridine, 3 , via the corresponding acetate $\mathbf{2}$ and subsequent saponification. Compound $\mathbf{3}$ acts as a cocatalyst for the ring-opening polymerization of $L$-lactide

The polymerization of $L$-lactide is carried out via a controlled coordinative ringopening polymerization of the lactide using aluminium alkoxide as the catalyst (Fig. 1) $[12,13]$. Compound 3 acts as a co-catalyst and is converted with triethyl aluminium to the corresponding aluminium alkoxide, which acts as insertion-polymerization center. Thereby, a terpyridine ligand becomes the head group of each polymer chain. The polymerization of L-lactide ((3S)-cis-3,6-dimethyl-1,4-dioxane-2,5-dione) is done in dry toluene for $48 \mathrm{~h}$ at $80^{\circ} \mathrm{C}$ and then stopped with water. The polymers are purified by repeated precipitation in methanol. Terpyridine end-capped poly(L-lactides), $\mathbf{4}$, were obtained with very narrow polydispersities and - to some extent - molecular weight control (Tab. 1). Due to the non-quantitative yields, which may result either from incomplete monomer conversion or from polymer loss during the work-up, precise statements about the degree of molecular weight control cannot be made yet. 
Tab. 1. GPC data of terpyridine end-capped poly(L-lactide)s with different molecular weights (solvent: $\mathrm{CHCl}_{3}$ )

\begin{tabular}{rrrrrr}
\hline No. & $\begin{array}{c}\overline{\mathbf{M}}_{\mathbf{n}} \\
\text { (RI) }\end{array}$ & $\begin{array}{c}\overline{\mathbf{M}}_{\mathrm{w}} \\
\text { (RI) }\end{array}$ & $\overline{\mathbf{M}}_{\mathrm{w}} / \overline{\mathbf{M}}_{\mathbf{n}}$ & $\begin{array}{c}\text { Yield in } \\
\text { \% }\end{array}$ & $\begin{array}{c}\text { Calculated } \\
\text { masses } \\
\text { (from }\left[\mathbf{M}_{\mathbf{0}} / \mathbf{I}_{\mathbf{0}}\right] \text { ) } \\
\mathbf{g} / \mathbf{m o l}\end{array}$ \\
\hline 4a & 11230 & 12960 & 1.15 & 81 & 12000 \\
4b & 8900 & 9800 & 1.10 & 92 & 10000 \\
4c & 3960 & 5010 & 1.26 & 83 & 5000 \\
4d & 3200 & 3510 & 1.09 & 90 & 3500
\end{tabular}

Besides GPC, MALDI-TOF mass spectrometry is a useful method for mass resolved structural and end-group analysis of polymer chains. It explicitly shows the formation of the expected terpyridine end-capped poly(lactide)s. Fig. 2 illustrates the MALDITOF-MS of polymer 4c. In addition to the narrow molecular weight distribution of the polymer, the discretely resolved molecular mass peaks are shown and can be assigned to the corresponding polymer chains. Thus the mass peak at $\mathrm{m} / \mathrm{z}=1781$ corresponds within the measuring accuracy to a terpyridine end-capped polymer with 10 lactide units $\left(10 \times 144.04 \mathrm{~g} / \mathrm{mol}_{\text {lactide }}+322.3 \mathrm{~g} / \mathrm{mol}_{\text {tpy }}+17.0 \mathrm{~g} / \mathrm{mol}_{\mathrm{OH}}=1779.7\right.$ $\mathrm{g} / \mathrm{mol}$ ). It is notable that the interval between each peak is $\mathrm{m} / \mathrm{z}=72$. This corresponds to one ester unit and therefore to half of a lactide unit. The reason for this phenomenon is the occurrence of an ester exchange process during the insertion polymerization by inter- and intramolecular reactions of the ester functions (transesterification) [14].

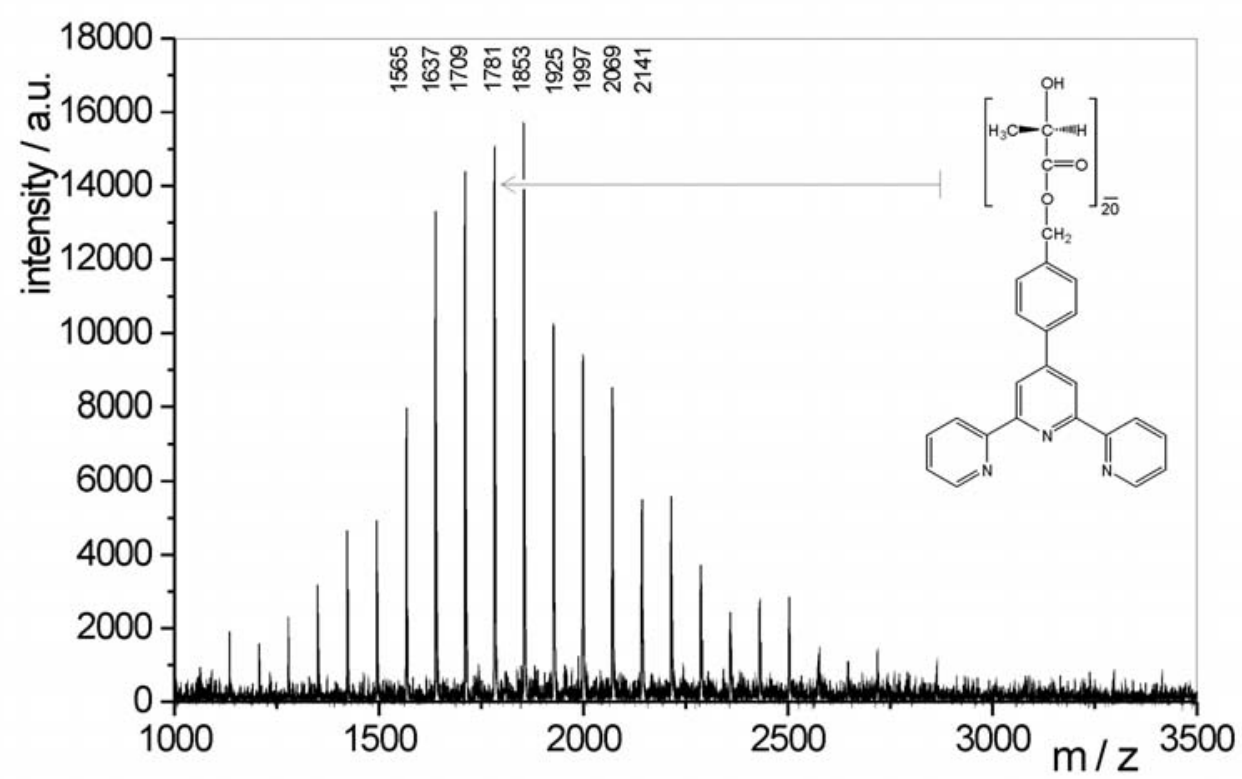

Fig. 2. MALDI-TOF mass spectrum of poly(L-lactide) $4 \mathrm{c}$. The mass peak at $\mathrm{m} / \mathrm{z}=$ 1781 corresponds to a polymer with 20 ester units in the chain (linear mode, matrix: $\alpha$-cyano-4-hydroxycinnamic acid)

${ }^{1} \mathrm{H}$ NMR spectroscopy is an important supplementary characterization method. In Fig. 3 , the spectrum of polymer $\mathbf{4 b}$ is shown. Apart from the proton signals of the 
polymer at $1.56 \mathrm{ppm}\left(\mathrm{CH}_{3}\right.$, doublet) and $5.14 \mathrm{ppm}(\mathrm{C}-\mathrm{H}$, quartet), the weak signals of the aromatic terpyridine protons are also detected between 7.34 and $8.70 \mathrm{ppm}$. This verifies the incorporation of the 2,2':6',2"-terpyridine at the end of the polymer chain. The enlarged insets reveal the corresponding coupling patterns and allow the assignment to the proton-positions. The ratio of the integral values of the terpyridine and the poly(lactide) protons directly yields the monomer/initiator ratio and, therefore, the number-average molecular weight $\left(\mathrm{M}_{\mathrm{n}}\right)$ of the polymer. In the presented spectra, the analysis of the integrals results in a monomer/initiator ratio of 68 which fits exactly to the predefined ratio set at the beginning of the polymerization.

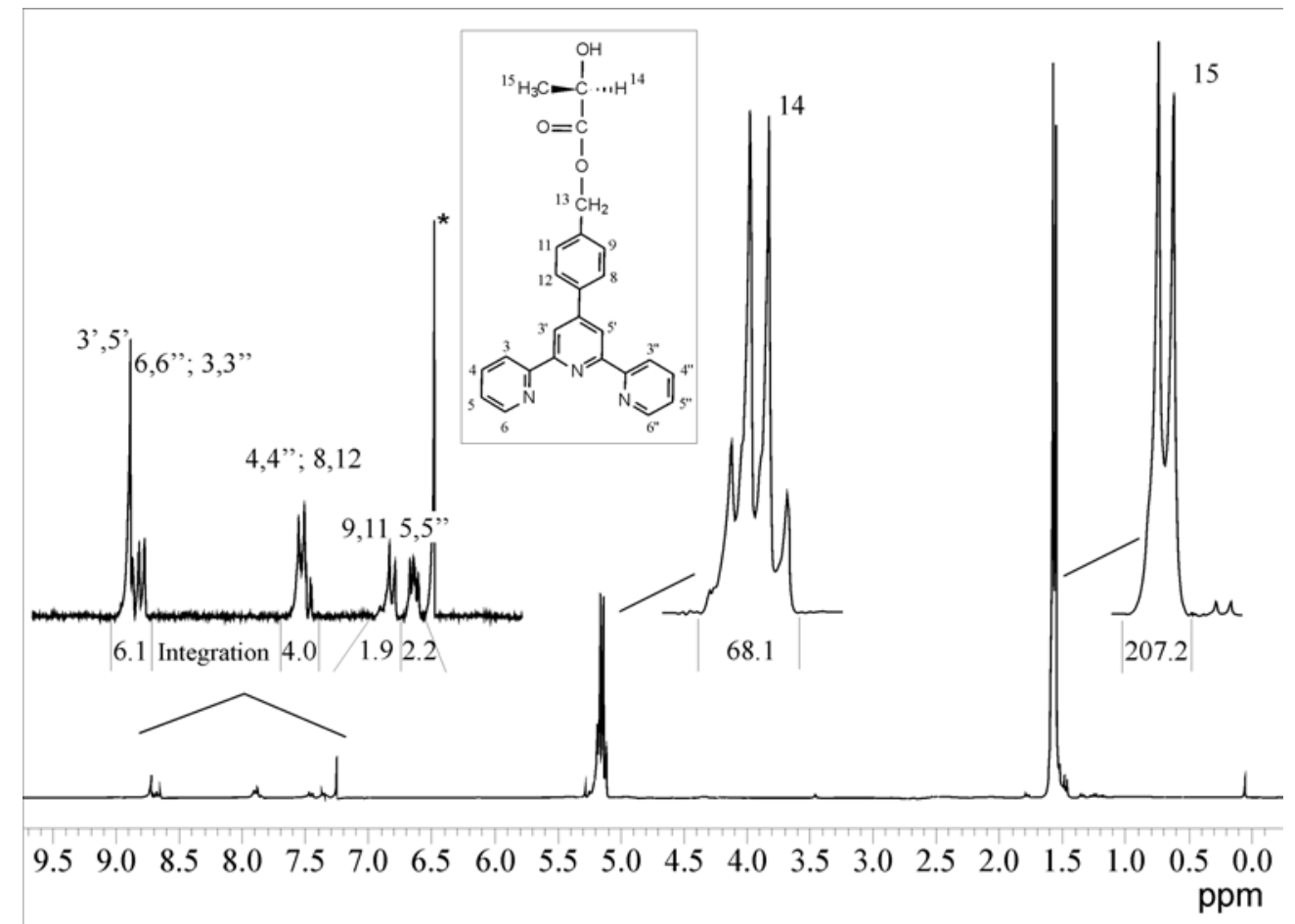

Fig. 3. ${ }^{1} \mathrm{H}$ NMR spectrum of terpyridine end-capped poly $(L$-lactide $) \mathbf{4 b}$ in $\mathrm{CDCl}_{3}\left(^{*}\right)$. The insets show the coupling patterns, the proton-assignment and the corresponding integral values

As every poly( $L$-lactide) chain end contains one $2,2^{\prime}: 6^{\prime}, 2^{\prime \prime}$-terpyridine unit, these polymers can be considered as macroligands. Therefore, complexation of these polymers with transition metal ions offers an interesting field of investigation. Up to now, such experiments have been carried out with similar bipyridine end-capped polymers, which were complexed with iron(II), ruthenium(II) or copper(I) [7,15-17]. We already presented the complexation of related terpyridine derivatives with iron(II) and could show that the formed polymer complexes reveal outstanding stability [9]. In contrast to the bipyridine systems, no shear-force sensitivity was observed and, therefore, the verification of the supramolecular polymer complexes by GPC measurements rendered possible.

The complexation of the terpyridine poly(lactide)s with $\mathrm{Fe}(\mathrm{II})$ (Fig. 4) must be performed under phase-transfer conditions due to the different polarities of the hydrophobic polymers and the hydrophilic iron salt. Therefore, the poly(lactide) $\mathbf{4 d}$ and $\mathbf{4 b}$, respectively, $\mathrm{FeSO}_{4} \times 7 \mathrm{H}_{2} \mathrm{O}$ and (butyl) ${ }_{4} \mathrm{NBr}$ as phase-transfer agent were stirred in a two-phase system of chloroform, water and acetone for $24 \mathrm{~h}$ at room 
temperature. The complexed polymer was precipitated from the hydrophobic phase in cold methanol. In Tab. 2, the GPC data of two complexed poly(L-lactide)s 5a and $\mathbf{5 b}$ (yielded from the macroligands $\mathbf{4 d}$ and $\mathbf{4 b}$, respectively) are presented. The doubling of the average molecular weight and only slight broadening of the polydispersity can be observed.<smiles>CC(C)(O)C(=O)COc1ccc(-c2cc(-c3ccccn3)nc(-c3ccccn3)c2)cc1</smiles>

$4 c, d$

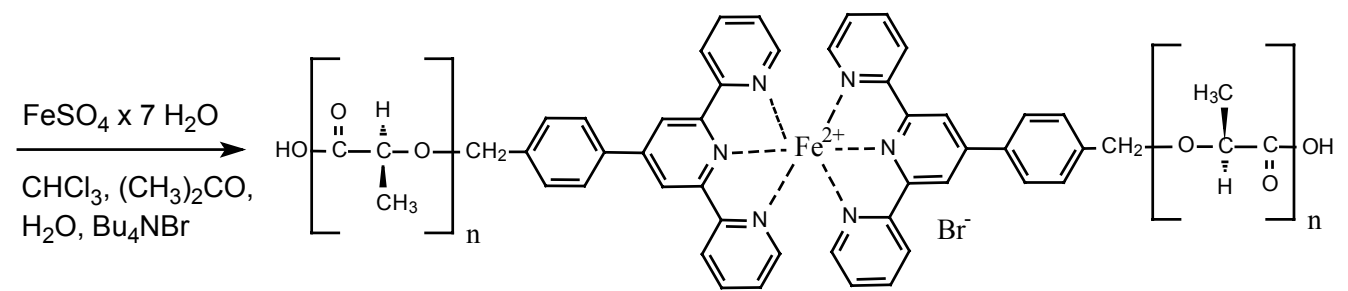

5a,b

Fig. 4. Complexation of poly(L-lactide) macroligands with iron(II) under phase transfer conditions

Tab. 2. GPC data of terpyridine end-capped poly(L-lactide)s complexed with iron(II) (solvent: $\mathrm{CHCl}_{3}$ )

\begin{tabular}{rrrrcr}
\hline No. & $\begin{array}{r}\overline{\mathbf{M}}_{\mathrm{n}} \\
(\mathbf{R I})\end{array}$ & $\begin{array}{c}\overline{\mathbf{M}}_{\mathrm{w}} \\
(\mathbf{R I})\end{array}$ & $\overline{\mathbf{M}}_{\mathrm{w}} / \overline{\mathrm{M}}_{\mathrm{n}}$ & Yield in \% & $\begin{array}{c}\text { from } \\
\text { macroligand }\end{array}$ \\
\hline 5a & 5430 & 6830 & 1.26 & 90 & $\mathbf{4 d}$ \\
5b & 12490 & 15220 & 1.22 & 95 & $\mathbf{4 b}$
\end{tabular}

The UV-Vis spectrum of compound 5a reveals the successful formation of the Fe(II) poly(lactide) (Fig. 5a). The specific metal-ligand charge-transfer band of the iron(II) terpyridine complex at $\lambda=580 \mathrm{~nm}$ is observed for both the polymer complex and a reference $\mathrm{Fe}(\mathrm{II})$ complex of the hydroxymethyl-functionalized terpyridine 3 . Nevertheless, the UV-Vis spectra provides no information about the completeness of polymer complex formation whereas GPC measurements do. In Fig. 5b, the GPC curves of the uncomplexed poly( $L$-lactide) $\mathbf{4 d}$ and the corresponding complexed species $\mathbf{5 a}$ are presented. The doubling of the average molecular weight after complexation demonstrates complete conversion. The polydispersity of compound $\mathbf{5 a}$ $\left(M_{w} / M_{n}=1.26\right)$ is only slightly broader than the one of compound $4 \mathbf{d}\left(M_{w} / M_{n}=1.09\right)$.

The combination of GPC and UV-Vis spectrometry supplies evidence for the formation of the supramolecular dimeric species. Therefore, GPC detection is performed by an in-line diode array UV/Vis spectrophotometer. Fig. 6 presents the resulting 3D correlation of the elution volume and the UV-Vis data. The typical (monomodal) charge transfer band of the iron(II) terpyridine complex at $\lambda=580 \mathrm{~nm}$ as well as the additional $\pi-\pi^{*}$-transition at $\lambda \approx 300 \mathrm{~nm}$ can be observed for the poly(lactide) complex 5a. This proves that no fragmentation of the supramolecular polymer complex occurs on the GPC column and thereby reveals the outstanding stability of terpyridine-based polymer complexes compared to analogous bipyridine 
systems [17]. The inset shows the corresponding spectra of macroligand $\mathbf{4 d}$. The $\pi-\pi^{*}$-transition of uncomplexed terpyridine aromatics at $\lambda=284 \mathrm{~nm}$ can be seen.

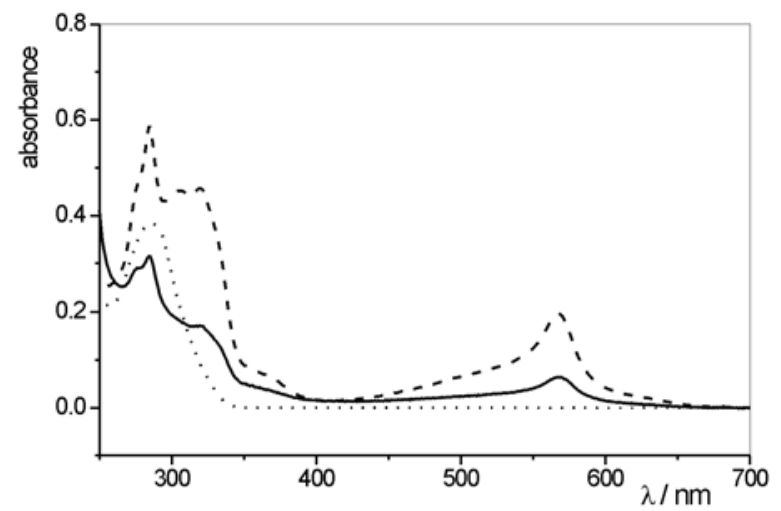

a)

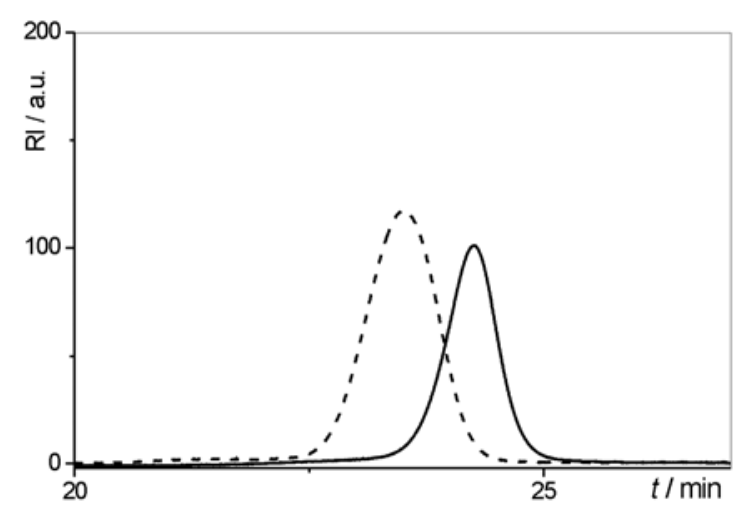

b)

Fig. 5. Complexation of poly(L-lactide) macroligands with iron(II) under phase transfer conditions. a) UV-Vis spectra of the Fe(II) poly(lactide) complex (-), a reference $\mathrm{Fe}(\mathrm{II})$ complex of compound 3 (-----), and the uncomplexed ligand $\mathbf{3}(\cdots \cdots)$ in $\mathrm{CH}_{3} \mathrm{CN}$. b) GPC curves of poly(lactide) macroligand $\mathbf{4 d}(-)$, and the corresponding $\mathrm{Fe}(\mathrm{II})$ complex 5a (-----) in $\mathrm{CHCl}_{3}$

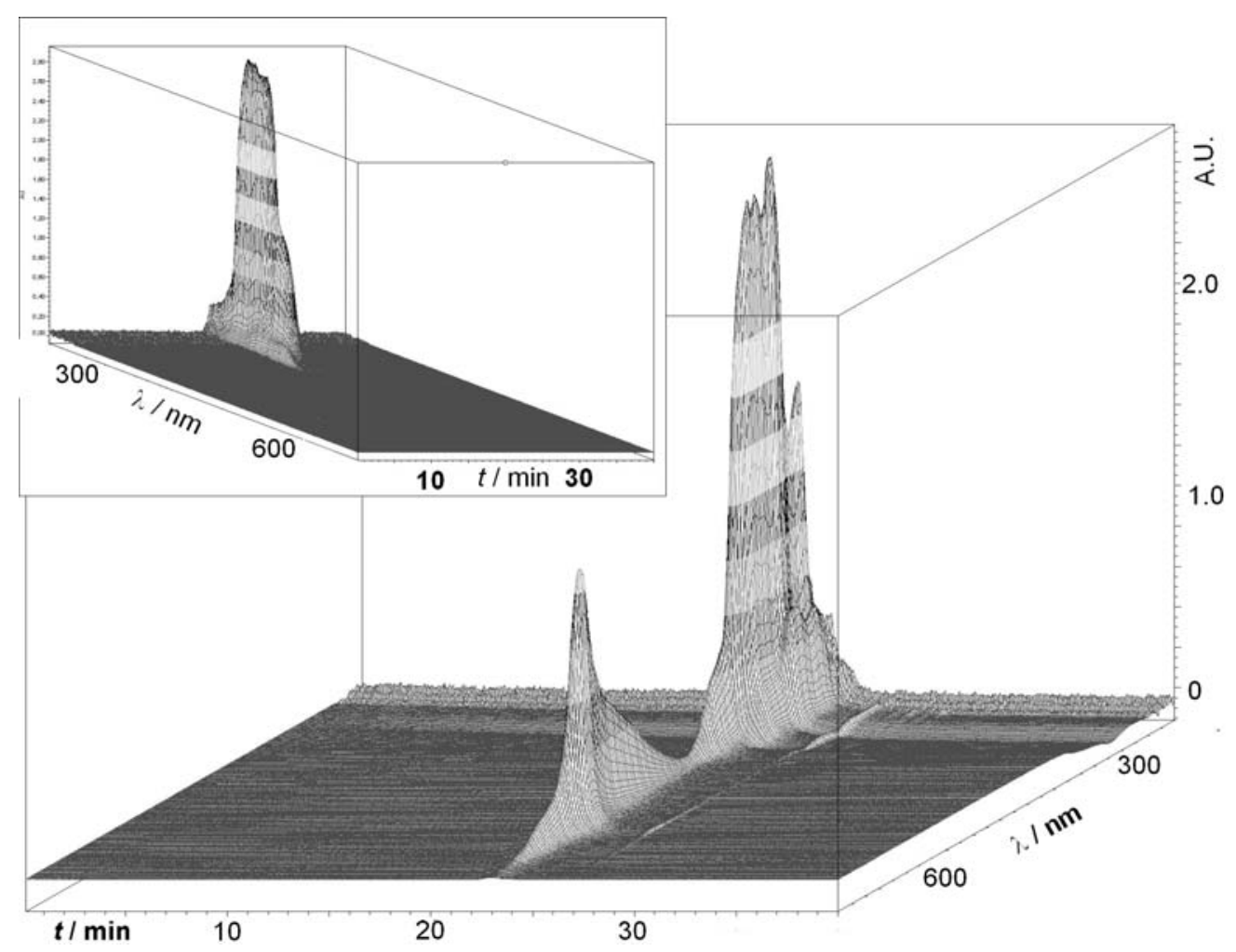

Fig. 6. GPC in-line diode array spectroscopic plots of poly(L-lactide) macroligand $\mathbf{4 b}$ (inset) and the corresponding dimer iron(II) complex 5a (main figure). Solvent: $\mathrm{CDCl}_{3}$

Finally, MALDI-TOF mass spectrometry demonstrates the formation of the poly(lactide) $\mathrm{Fe}$ (II) complex (Fig. 7). Apart from the doubling of the molecular weight distribution (around 2000 - 5000 dalton) compared to macroligand 4b (1000 - 2500 dalton), it is possible to assign the MALDI-TOF-MS signals to single macromolecular 
chains. The inset shows an expanded portion of the spectrum with three distinct mass series due to aggregates with $\mathrm{Na}^{+}$and $\mathrm{K}^{+}$ions. Calculation was done on the basis of one bromide counterion, which is presumed to attach during the phase transfer process via ${ }^{t} \mathrm{Bu} 4 \mathrm{NBr}$.

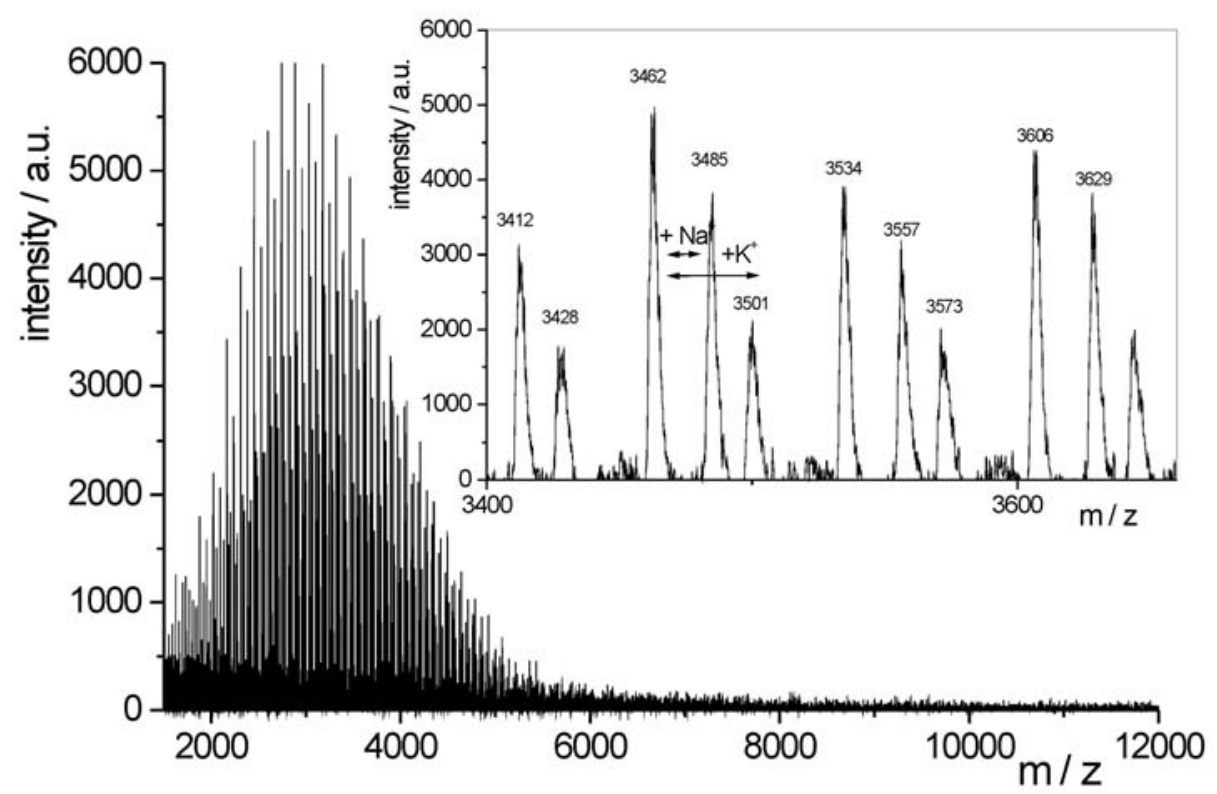

Fig. 7. MALDI-TOF MS of Fe(II) complexed poly(lactide) $\mathbf{5 a}$, obtained in linear mode using $\alpha$-cyano-4-hydroxycinnamic acid as matrix

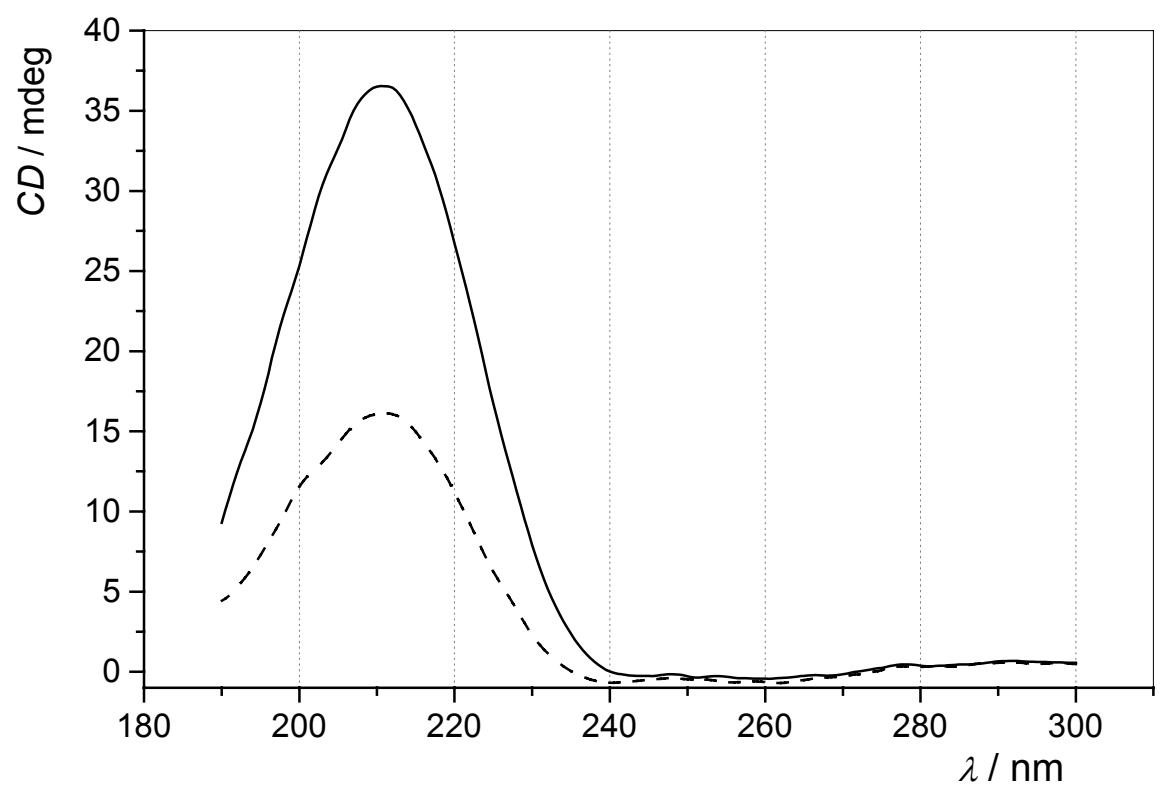

Fig. 8. CD spectra of poly(L-lactid)e $5 \mathbf{b}$ at different concentrations: $1.06 \times 10^{-4} \mathrm{~g} / \mathrm{ml}$ $(-) ; 5.3 \times 10^{-5} \mathrm{~g} / \mathrm{ml}(----)$. Solvent $\mathrm{CH}_{3} \mathrm{CN}$; cell diameter $0.5 \mathrm{~cm}$

Due to the chirality of the utilized monomer L-lactide, the obtained polymers display optical activity. This was proven by circular dichroism (CD). The CD spectra of the poly $(L$-lactide) macroligands reveal a positive dichroic band at $\lambda=210 \mathrm{~nm}$ as it is known for optically active poly(lactide)s (Fig. 8) [18,19]. This Cotton effect can be 
attributed to the $\mathrm{n} \rightarrow \pi *$ absorption of the ester group [20]. The intensity/concentration coefficient of the $C D$ band corresponds with those found for poly(L-lactide)s with high optical purity [19]. This signifies that transesterifications during the polymerization process do not cause evident racemisation. Moreover, the polymer complexes 5a and $\mathbf{5 b}$ showed thermochromic behavior. The purple color of such polymer films fades away after heating them over $160^{\circ} \mathrm{C}$. The color returns directly after cooling and appears to reach the starting intensity below $120^{\circ} \mathrm{C}$.

\section{Conclusions}

Poly(L-lactide) macroligands are accessible by the use of the novel 4'-(4-hydroxymethylphenyl)-2,2':6',2"-terpyridine ligand 3 as co-initiator. The coordinative ringopening polymerization of $L$-lactide proved to be a suitable method for the preparation of well-defined biodegradable poly $(L$-lactide)s end-capped with the tridentate terpyridine ligands. These macroligands can be easily complexed with iron(II) ions under phase transfer conditions to yield supramolecular poly( $L$-lactide) complexes. Due to their outstanding stability, an investigation using GPC was possible and showed a doubling of the average molecular weight after the complexation process. In-line diode array spectroscopy proved that there is no fragmentation of the dimers on the GPC column. The formation of both the macroligands and their iron(II) complexes could be demonstrated by a number of characterization methods, such as GPC, ${ }^{1} \mathrm{H}$ NMR spectroscopy, UV-Vis spectroscopy and MALDI-TOF mass spectrometry. Heating of the $\mathrm{Fe}(\mathrm{II})$ polymer films resulted in a reversible thermochromic effect.

These findings may be the first steps towards the switching of material properties by complexation processes or towards medicinal receptors.

\section{Experimental part}

\section{Materials}

In-line diode array GPC measurements were carried out with a Waters 996 Photodiode Array Detector and a Waters 717plus Autosampler GPC.

MALDI-TOF MS: PE Biosystems Voyager System 6020.

NMR: Bruker ARX 300; ${ }^{1} \mathrm{H}$ NMR: $300.13 \mathrm{MHz},{ }^{13} \mathrm{C}$ NMR: $75.47 \mathrm{MHz}\left(27^{\circ} \mathrm{C}\right)$, calibration/standard: $\mathrm{CDCl}_{3}, \mathrm{CD}_{3} \mathrm{CN}$.

Commercial chemical substances were supplied by Sigma-Aldrich $\mathrm{GmbH}$. For the synthesis of 4'-(4-bromomethylphenyl)-2,2':6',2"-terpyridine, $\mathbf{1}$, see ref. [21-23].

\section{Preparation of 4'-(4-acetylmethylphenyl)-2,2':6', 2"-terpyridine, 2}

4'-(4-Bromomethylphenyl)-2,2':6,2"-terpyridine, $1(2.0 \mathrm{~g}, 5.0 \mathrm{mmol})$ was dissolved in pure acetic acid $(40 \mathrm{ml})$, and dry sodium acetate $(410 \mathrm{mg}, 5.0 \mathrm{mmol})$ was added. The mixture was refluxed for $2 \mathrm{~h}$. After cooling, the solution was added dropwise to cold aqueous ammonia $(150 \mathrm{ml}, 10 \%)$. The precipitate was extracted with dichloromethane $(3 \times 20 \mathrm{ml})$. The organic phases were washed with water and brine and dried over $\mathrm{Na}_{2} \mathrm{SO}_{4}$. After removal of the solvent, the crude product was crystallized from ethyl acetate to yield a white solid $(1.52 \mathrm{~g}, 80 \%)$. m.p. $156^{\circ} \mathrm{C}$. 
${ }^{1} \mathrm{H}$ NMR $\left(\mathrm{CDCl}_{3}\right): \delta=2.12\left(\mathrm{~s}, \mathrm{H}^{15}, 3 \mathrm{H}\right), 5.16\left(\mathrm{~s}, \mathrm{H}^{13}, 2 \mathrm{H}\right), 7.33\left(\mathrm{~m}, \mathrm{H}^{5,5^{\prime \prime}}, 2 \mathrm{H}\right), 7.47$ $\left(\mathrm{d}, \mathrm{H}^{9,11}, J=8.2 \mathrm{~Hz}, 2 \mathrm{H},\right), 7.88\left(\mathrm{~m}, \mathrm{H}^{4,4^{\prime \prime}, 8,12}, 4 \mathrm{H}\right), 8.65\left(\mathrm{~d}, \mathrm{H}^{3,3^{\prime \prime}}, J=8.01 \mathrm{~Hz}, 2 \mathrm{H}\right)$, $8.70\left(\mathrm{~m}, \mathrm{H}^{6,6^{\prime \prime}}, 2 \mathrm{H}\right), 8.72\left(\mathrm{~s}, \mathrm{H}^{35^{\prime}}, 2 \mathrm{H}\right)$.

${ }^{13} \mathrm{C} \mathrm{NMR}\left(\mathrm{CDCl}_{3}\right): \delta=21.41\left(\mathrm{C}^{15}\right), 66.27\left(\mathrm{C}^{13}\right), 119.23\left(\mathrm{C}^{3,5}\right), 121.77\left(\mathrm{C}^{5,5^{\prime \prime}}\right), 124.24$ $\left(C^{3,3 "}\right), 127.92\left(C^{8,12}\right), 129.12\left(C^{9,11}\right), 137.21\left(C^{4,4 "}\right), 137.28\left(C^{7}\right), 138.82\left(C^{10}\right), 149.50$ $\left(C^{6,6^{\prime \prime}}\right), 150.11\left(C^{4^{\prime}}\right), 156.36\left(C^{2,2^{\prime \prime}}\right), 156.56\left(C^{2,6}\right), 171.24\left(C^{14}\right)$.

MS (El, 70eV); m/z (\%): 381 (100) [M+].

$\begin{array}{lllll}\mathrm{C}_{24} \mathrm{H}_{19} \mathrm{~N}_{3} \mathrm{O}_{2} \text { (381.43): } & \text { Calc. } & \mathrm{C} 75.51 & \mathrm{H} 4.98 & \mathrm{~N} 11.01 \\ & \text { Found } & \mathrm{C} 75.13 & \mathrm{H} 5.09 & \mathrm{~N} 10.98\end{array}$

Preparation of 4'-(4-hydroxymethylphenyl)-2,2':6', 2"-terpyridine, 3

4'-(4-Acetylmethylphenyl)-2,2':6',2"-terpyridine, $2(1 \mathrm{~g}, 2.6 \mathrm{mmol})$ was dissolved in tetrahydrofuran $(30 \mathrm{ml})$. After addition of aqueous $\mathrm{NaOH}(10 \mathrm{ml}, 10 \%)$, the mixture was refluxed for $3 \mathrm{~h}$. After cooling, extraction with dichloromethane $(3 \times 10 \mathrm{ml})$ was carried out. The organic phase was washed with saturated aq. $\mathrm{NaHCO}_{3}$ and water (20 ml each) and dried over $\mathrm{Na}_{2} \mathrm{SO}_{4}$. After removal of the solvent, the crude product was crystallized from chloroform to obtain a white solid $(0.61 \mathrm{~g}, 70 \%)$. m.p. $198^{\circ} \mathrm{C}$.

${ }^{1} \mathrm{H}$ NMR $\left(\mathrm{CDCl}_{3}\right): \delta=4.76\left(\mathrm{~s}, \mathrm{H}^{13}, 2 \mathrm{H}\right), 7.34\left(\mathrm{~m}, \mathrm{H}^{5,5 "}, 2 \mathrm{H}\right), 7.47\left(\mathrm{~d}, \mathrm{H}^{9,11}, J=8.2 \mathrm{~Hz}\right.$, $2 \mathrm{H},), 7.87\left(\mathrm{~m}, \mathrm{H}^{4,4 " 8,12}, 4 \mathrm{H}\right), 8.65\left(\mathrm{~d}, \mathrm{H}^{3,3^{\prime \prime}}, J=8.01 \mathrm{~Hz}, 2 \mathrm{H}\right), 8.70\left(\mathrm{~m}, \mathrm{H}^{6,6 "}, 2 \mathrm{H}\right)$, $8.71\left(\mathrm{~s}, \mathrm{H}^{35^{\prime}}, 2 \mathrm{H}\right)$.

${ }^{13} \mathrm{C}$ NMR $\left(\mathrm{CDCl}_{3}\right): \delta=65.25\left(\mathrm{C}^{13}\right), 119.23\left(\mathrm{C}^{3,5}\right), 121.85\left(\mathrm{C}^{5,5^{\prime \prime}}\right), 124.24\left(\mathrm{C}^{3,33^{\prime \prime}}\right)$, $127.80\left(C^{8,12}\right), 127.85\left(C^{9,11}\right), 137.39\left(C^{4,4}\right), 137.96\left(C^{7}\right), 142.34\left(C^{10}\right), 149.42\left(C^{6,66^{\prime}}\right)$, $150.33\left(C^{4^{\prime}}\right), 156.21\left(C^{2,2^{\prime \prime}}\right), 156.57\left(C^{2,66^{\prime}}\right)$.

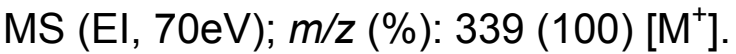

UV/VIS $\left(\mathrm{CH}_{3} \mathrm{CN}\right): \lambda_{\max } / \mathrm{nm}\left(\varepsilon /\left(\mid \cdot \mathrm{mol}^{-1} \cdot \mathrm{cm}^{-1}\right)\right)=227$ (16270), $286(32870)$.

$\begin{array}{lllll}\mathrm{C}_{22} \mathrm{H}_{17} \mathrm{~N}_{3} \mathrm{O}(339.39) & \text { Calc. } & \mathrm{C} 77.86 & \mathrm{H} 5.05 & \mathrm{~N} 12.38 \\ & \text { Found } & \mathrm{C} 77.47 & \mathrm{H} 4.90 & \mathrm{~N} 12.20\end{array}$

\section{Preparation of poly(L-lactide) macroligands, 4}

The polymerizations were carried out in silanized schlenk tubes under nitrogen. 4'-(4Hydroxymethylphenyl)-2,2':6',2"-terpyridine, 3 , was dissolved in dry toluene $(10 \mathrm{mg} / 6 \mathrm{ml})$, and triethylaluminium (0.33 equivalents per $\mathrm{OH}$ unit) was added. The reaction mixture was stirred for $30 \mathrm{~min}$ at room temperature. Afterwards, the monomer (3S)-cis-3,6-dimethyl-1,4-dioxane-2,5-dione (recrystallized from ethyl acetate) was added (the amount was calculated with respect to the desired molecular weights) and the mixture was stirred at $80^{\circ} \mathrm{C}$ for 2 days. The reaction was then quenched with methanol. After removal of the solvent, the residue was dissolved in a small quantity of dichloromethane and afterwards poured into cold methanol. The precipitated polymer was filtrated and dried in vacuo.

${ }^{1} \mathrm{H}$ NMR $\left(\mathrm{CDCl}_{3}\right): \delta(\mathrm{ppm}) 1.55\left(\mathrm{~d}, \mathrm{H}^{10}, J=7.05 \mathrm{~Hz}, 195 \mathrm{H}\right), 5.14\left(\mathrm{q}, \mathrm{H}^{9}, J=7.05 \mathrm{~Hz}\right.$, $65 \mathrm{H}), 7.34\left(\mathrm{~m}, \mathrm{H}^{2}, 2 \mathrm{H}\right), 7.45\left(\mathrm{~d}, \mathrm{H}^{7}, J=8.19 \mathrm{~Hz}, 2 \mathrm{H},\right), 7.87\left(\mathrm{~m}, \mathrm{H}^{3.6}, 4 \mathrm{H}\right), 8.65\left(\mathrm{~d}, \mathrm{H}^{4}\right.$, $J=8.01 \mathrm{~Hz}, 2 \mathrm{H}), 8.70\left(\mathrm{~m}, \mathrm{H}^{1}, 2 \mathrm{H}\right), 8.71\left(\mathrm{~s}, \mathrm{H}^{5}, 2 \mathrm{H}\right)$.

UV/VIS $\left(\mathrm{CH}_{3} \mathrm{CN}\right): \lambda_{\max } / \mathrm{nm}=284$. 


\section{Preparation of poly(L-lactide) iron(II) complexes, $\mathbf{5}$}

The poly(lactide) $\left(100 \mathrm{mg}\right.$ ) was dissolved in $\mathrm{CHCl}_{3}(10 \mathrm{ml})$. An excess of $\mathrm{FeSO}_{4} \mathrm{x}$ $7 \mathrm{H}_{2} \mathrm{O}$ was dissolved in water $(5 \mathrm{ml})$ and added to the polymer solution. To generate phase transfer conditions, $5 \mathrm{ml}$ of acetone and $10 \mathrm{mg}$ of tetrabutylammonium bromide was added and the mixture was stirred at room temperature for $24 \mathrm{~h}$. The violet organic phase was separated, washed with water and brine, dried with $\mathrm{Na}_{2} \mathrm{SO}_{4}$ and poured into cold methanol. The purple precipitate was filtered off and dried in vacuo.

UV/VIS $\left(\mathrm{CH}_{3} \mathrm{CN}\right): \lambda_{\max } / \mathrm{nm}=286,306,319,568$ (metal-to-ligand charge transfer band).

Acknowledgement: The research was supported by the Fonds der Chemischen Industrie, the Deutsche Forschungsgemeinschaft (Schu 1229/5-1, HeisenbergProgram and SFB 563) and the BAYER AG. We thank O. Nuyken for his support.

[1] Schubert, U. S.; Eschbaumer, C.; Angew. Chem. Chem. Int. 2001, in press.

[2] Schubert, U. S.; Heller, M.; Chem. Eur. J. 2001, 7, 5252.

[3] Schubert, U. S.; Nuyken, O.; Hochwimmer, G.; J. Macromol. Sci. 2000, A37, 645.

[4] McAlvin, J. E.; Scott, S. B.; Fraser, C. L.; Macromolecules 2000, 33, 6953.

[5] Wu, X.; Collins, J. E.; McAlvin, J. E.; Cutts, R. W.; Fraser, C. L.; Macromolecules 2001, 33, 4053.

[6] Fraser, C. L.; Smith, A. P.; J. Polym. Sci., Part A: Polym. Chem. 2000, 38, 4704.

[7] Corbin, P. S.; Webb, M. P.; McAlvin, J. E.; Fraser, C. L.; Biomacromolecules 2001, 2, 223.

[8] Heller, M.; Schubert, U. S.; Macromol. Symp. 2002, 177, 87.

[9] Heller, M.; Schubert, U. S.; Macromol. Rapid Commun. 2001, 22, 1358.

[10] Jain, R.; Shah, N. H.; Malick, A. W.; Rhodes, C. T.; Drug Dev. Ind. Pharm. 1998, 24, 703.

[11] Langer, R.; Acc. Chem. Res. 2000, 33, 94.

[12] Kricheldorf, H. R.; Damrau, D.-O.; J. Macromol. Sci., Pure Appl. Chem. 1998, 35, 1875

[13] Kricheldorf, H. R.; Berl, M.; Scharnagl, N.; Macromolecules 1988, 21, 286.

[14] Montaudo, G.; Montaudo, M. S.; Puglisi, C.; Samperi, F.; Spassky, N.; LeBorgne, A.; Wisniewski, M.; Macromolecules 1996, 29, 6461.

[15] Schubert, U. S.; Hochwimmer, G.; Macromol. Rapid Commun. 2001, 22, 274.

[16] Schubert, U. S.; Hochwimmer, G.; Polym. Prepr. 2000, 41, 433.

[17] Corbin, P. S.; McAlvin, J. E.; Webb, M. P.; Shenoy, S.; Fraser, C. L.; Polym. Prepr. 2000, 41, 1199.

[18] Goodmann, M.; D'Alagni, M.; Polym. Lett. 1967, 5, 515.

[19] Bartus, J.; Weng, D.; Vogl, O.; Polym. Int. 1994, 34, 433. 
[20] Schulz, R. C.; Guthmann, A.; Polym. Lett. 1967, 5, 1099.

[21] Bushell, K. L.; Couchman, S. M.; Jeffery, J. C.; Rees, L. H.; Ward, M. D.; J. Chem. Soc., Dalton Trans. 1998, 3397.

[22] Collin, J. P.; Heitz, V.; Sauvage, J. P.; Tetrahedron Lett. 1991, 32, 5977.

[23] Spahni, W.; Calzaferri, G.; Helv. Chim. Acta 1984, 67, 450. 